\title{
Retraction Note: Mountain bridge design based on remote sensing images
}

\author{
Zhaofeng Liu ${ }^{1} \cdot$ Xinyin $\mathrm{Wu}^{2}$
}

Published online: 22 November 2021

(c) Saudi Society for Geosciences 2021

Retraction Note: Arabian Journal of Geosciences (2021) 14: 1421

https://doi.org/10.1007/s12517-021-07746-4

The Editor-in-Chief and the Publisher have retracted this article because the content of this article is nonsensical. The peer review process was not carried out in accordance with the Publisher's peer review policy. The authors have not responded to correspondence regarding this retraction.

The original article can be found online at https://doi.org/10.1007/ s12517-021-07746-4.

\section{Xinyin Wu}

1 School of Building Engineering, Hunan Institute of Engineering, Xiangtan 411104, Hunan, China

2 Hunan Zhonglu Huacheng Bridge Technology Co, Ltd, Xiangtan 411100, Hunan, China 